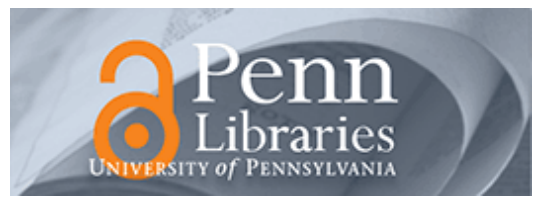

University of Pennsylvania

ScholarlyCommons

Finance Papers

Wharton Faculty Research

7-1985

Dynamic Behavior of Capital Accumulation in a Cash-in-Advance Model

Andrew B. Abel

University of Pennsylvania

Follow this and additional works at: https://repository.upenn.edu/fnce_papers

Part of the Economics Commons, and the Finance and Financial Management Commons

Recommended Citation

Abel, A. B. (1985). Dynamic Behavior of Capital Accumulation in a Cash-in-Advance Model. Journal of Monetary Economics, 16 (1), 55-71. http://dx.doi.org/10.1016/0304-3932(85)90006-6

This paper is posted at ScholarlyCommons. https://repository.upenn.edu/fnce_papers/185

For more information, please contact repository@pobox.upenn.edu. 


\title{
Dynamic Behavior of Capital Accumulation in a Cash-in-Advance Model
}

\author{
Abstract \\ This paper analyzes the dynamic behavior of capital accumulation in Stockman's cash-in-advance model. \\ If the cash-in-advance constraint applies only to consumption, then money is superneutral along the \\ transition path as well as in the long run. Alternatively, if the cash-in-advance constraint applies to gross \\ investment as well as consumption, then a permanent increase in the rate of monetary growth reduces \\ the steady state capital stock. The effect on the speed of adjustment depends on the sign of a certain \\ simple function of the parameters of preferences and technology. \\ Disciplines \\ Economics | Finance and Financial Management
}


NBER WORKING PAPER SERIES

DYNAMIC BEHAVIOR OF CAPITAL ACCUMULATION IN A

CASH-IN-ADVANCE MODEL

Andrew B. Abel

Working Paper No. 1549

NATIONAL BUREAU OF ECONOMIC RESEARCH 1050 Massachusetts Avenue

Cambridge, MA 02138

January 1985

I thank Alberto Alesina, Robert King, Nobuhiro Kiyotaki, and an anonymous referee for helpful comments and Stanley Fischer for helpful conversations. I also thank the National Science

Foundation for financial support. The research reported here is part of the NBER's research program in Economic Fluctuations. Any opinions expressed are those of the author and not those of the National Bureau of Economic Research. 
NBER Working Paper \#1549

January 1985

Dynamic Behavior of Capital

Accumulation in a

Cash-in-Advance Mode1

\section{ABSTRACT}

This paper analyzes the dynamic behavior of capital accumulation in Stockman's (1981) cash-in-advance model. If the cash-in-advance constraint applies only to consumption, then money is superneutral along the transition path as well as in the long run. Alternatively, if the cash-in-advance constraint applies to gross investment as well as consumption, then a permanent increase in the rate of monetary growth reduces the steady state capital stock. The effect on the speed of adjustment depends on the sign of a certain simple function of the parameters of preferences and technology.

Andrew B. Abel Department of Economics Harvard University Littauer Center 111 Cambridge, Massachusetts 02138 (617) 495-1869 
In an interesting recent paper, Stockman (1981) develops a model of an economy with capital and with a cash-in-advance constraint. His model produces the surprising result that if the cash-in-advance constraint applies to gross investment as well as consumption, then a permanent increase in the rate of monetary growth leads to a decrease in the steady state capital stock; if the cash-in-advance constraint applies only to consumption, then money is superneutral in the long run. It was left as "an open question whether (and how) the rate of monetary expansion affects the speed at which the economy approaches the steady state" (p. 391).

The current paper addresses the question of the effect of monetary growth on the adjustment speed and demonstrates that if the cash-in-advance constraint applies only to consumption, then money is superneutral along the transition path as well as in the long run. Alternatively, if the cash-in-advance constraint applies to gross investment as well as consurption, then the direction of the effect of increased monetary growth on the speed of adjustment depends on the sign of a certain simple function of the parameters of preferences and technology. For example, with an isoelastic utility function and a Cobb-Douglas production function, higher monetary growth leads to faster adjustment of the economy if capital does not depreciate. On the other hand, if capital completely depreciates after one period, then increased monetary growth leads to faster (slower) adjustment of the economy if the elasticity of marginal utility is less (greater) than one; with logarithmic utility, the speed of adjustment is invariant to the. rate of monetary growth. To be more precise, these results apply only in the neighborhood of the steady state, just as Fischer's (1979) and Asako's (1983) analyses of the Sidrauski (1967) model are limited to a neighborhood of the steady state. 
In section I we set up a general model which includes as special cases a cash-in-advance constraint for consumption and gross investment, and, alternatively, a cash-in-advance constraint for consumption only. Defining $\sigma \equiv \mathrm{M}_{t+1} / \mathrm{M}_{t}$ as the (gross) rate of monetary growth and letting $B$ be the discount factor applied to next period's utility, we show that the existence of a steady state requires $\sigma \geq \beta$. We also demonstrate that setting $\sigma$ equal to $\beta$ allows the economy to attain the Modified Golden Rule in the steady state. In section II we analyze the dynamic behavior of an economy in which cash is needed for consumption only. We show that if the cash-in-advance constraint is always binding, then a change in monetary growth has no effect on either the transition path or the steady state. Section III analyzes the dynamic behavior of an economy with a cash-in-advance constraint for investment as well as consumption. We demonstrate that the unique stable root of the linearized economy is positive so that the approach to the steady state is monotonic. In section IV we show that an increase in the rate of monetary growth leads to a faster speed of adjustment if and only if a certain simple function of the parameters of preferences and technology is positive. Concluding remarks are presented in section $\mathrm{V}$. 


\section{The Model}

The model in this paper is the same as in stockman (1981). A representative individual maximizes the utility function

$$
\sum_{t=0}^{\infty} \beta^{t} U\left(C_{t}\right) \quad 0<\beta<1 ; U^{\prime}>0 ; U^{\prime \prime}<0
$$

subject to a budget constraint and a cash-in-advance constraint. The individual can hold two assets, money and capital. Letting $\mathrm{K}_{t}$ and $\mathrm{M}_{t}$ denote the capital stock and the (nominal) balances, respectively, held at the beginning of period $t$, the budget constraint can be written as

$$
c_{t}+K_{t+1}+\frac{M_{t+1}}{P_{t}}=f\left(K_{t}\right)+(1-\delta) K_{t}+\frac{M_{t}+\tau}{P_{t}}
$$

where $C_{t}$ is consumption, $P_{t}$ is the money price of the homogeneous good, $\tau_{t}$ is the nominal money transfer received at the beginning of period $t$, and $\delta$ is the rate of physical depreciation of capital. The production function $f\left(k_{t}\right)$ is strictly increasing and strictly concave $\left(f^{\prime}>0, f^{\prime \prime}<0\right)$.

We consider two alternative formulations of the cash-in-advance constraint. In one formulation, we require that the nominal value of consumption during period $t$ be less than or equal to the money on hand at the beginning of period $t$

$$
C_{t} \leq\left(M_{t}+\tau_{t}\right) / P_{t}
$$

In the other formulation, we require that the nominal value of consumption plus gross investment during a period be less than or equal to the money on hand at the beginning of the period 


$$
C_{t}+K_{t+1}-(1-\delta) K_{t} \leq\left(M_{t}+\tau_{t}\right) / P_{t}
$$

It is convenient to define the parameter $\mu$ where $\mu=0$ indicates that we are considering the cash-in-advance constraint in ( 3 ) and $\mu=1$ indicates that we are considering the cash-in-advance constraint in (4). Then the consumer's optimization problem under each of the cash-in-advance constraints can be solved using the following Lagrangean

$$
\begin{aligned}
L=\sum_{t=0}^{\infty} \beta^{t}\left\{U\left(C_{t}\right)\right. & +\lambda_{t}\left(f\left(K_{t}\right)+(1-\delta) K_{t}+\frac{M_{t}+\tau_{t}}{P_{t}}-C_{t}-K_{t+1}-\frac{M_{t+1}}{P_{t}}\right) \\
& \left.+\gamma_{t}\left(\frac{M_{t}+\tau_{t}}{P_{t}}-C_{t}-\mu K_{t+1}+\mu(1-\delta) K_{t}\right)\right\}
\end{aligned}
$$

Differentiating (5) with respect to $C_{t}, K_{t}$, and $M_{t}$, we obtain

$$
\begin{gathered}
U^{\prime}\left(c_{t}\right)=\lambda_{t}+\gamma_{t} \\
\beta \lambda_{t+1}\left(f^{\prime}\left(K_{t+1}\right)+(1-\delta)\right)+\beta \mu \gamma_{t+1}(1-\delta)=\lambda_{t}+\mu \gamma_{t} \\
\frac{\beta}{P_{t+1}}\left(\lambda_{t+1}+\gamma_{t+1}\right)=\frac{\lambda_{t}}{P_{t}}
\end{gathered}
$$

If $\mu=1$, then equations $(6 a-c)$ are identical to stockman's equations $(3)-(5)$. The first-order conditions in $(6 a-c)$ are more easily interpreted in the special cases in which $\mu=0$ and $\mu=1$; we defer this interpretation to sections II and III, respectively. Before examining these special cases, we briefly examine the steady state in the general case.

The steady state, if it exists, is characterized by a constant capital 
stock, $K$, a constant level of consumption, $C$, and a constant (gross) rate of inflation, $\Pi_{t} \equiv P_{t} / P_{t-1}$, which is equal to the constant (gross) rate of monetary growth $\sigma \equiv M_{t} / M_{t-1}$. In addition, the shadow prices $\lambda_{t}$ and $\gamma_{t}$ are constant. It follows immediately from $(6 \mathrm{c})$ that in the steady state

$$
\gamma=\lambda\left(\frac{\sigma}{\beta}-1\right)
$$

Since $\gamma_{t}$ is the Lagrange multiplier associated with the cash-in-advance constraint, it is clear that this constraint is strictly binding if and only if the (gross) rate of monetary growth exceeds $\beta$. If $\sigma=\beta$, then this constraint is not strictly binding.

A steady state does not exist if $\sigma<\beta$, as may be seen formally by observing from (7) that $\sigma<\beta$ implies $\gamma<0$ which violates the Kuhn-Tucker condition that $\gamma_{t} \geq 0$ for all $t .^{1}$ A more intuitive explanation for the non-existence of a steady state when $\sigma<\beta$ is obtained by considering consuming one unit less at time $t$ and holding $P_{t}$ more units of money. This money can be used to buy $1 / \Pi_{t+1}$ units of consumption at time $t+1$. Thus, this small change will change the net present value of utility by $-U^{\prime}\left(C_{t}\right)+\beta U^{\prime}\left(C_{t+1}\right) / \Pi_{t+1}$. In a steady state $\Pi_{t+1}=\sigma$ and the change in utility is $\left(\frac{\beta}{\sigma}-1\right) u^{\prime}(C)$. If $\sigma<\beta$ then this change leads to an increase in utility and the original situation could not have been optimal.

The steady state capital stock is easily characterized by substituting (7) into $(6 \mathrm{~b})$ to obtain

$$
\beta\left(f^{\prime}(K)+1-\delta\right)=1+\mu\left(\frac{\sigma}{\beta}-1\right)(1-\beta(1-\delta))
$$

1. This statement is based on the fact that in the steady state $\lambda>0$. To establish this fact, substitute $(6 a)$ into $(6 c)$ and use the fact that $\Pi=\sigma$ in the steady state to obtain $\beta U^{\prime}(C)=\sigma \lambda$ which implies $\lambda>0$. 
As a benchmark for comparison, we define $\hat{k}$ to be the Modified Golden Rule capital stock in an economy without a cash-in-advance constraint. It is well-known (see, for example, Samuelson (1968)) that

$$
B\left(f^{\prime}(\hat{K})+I-\delta\right)=I
$$

Observe from (8) and (9) that the cash-in-advance economy achieves the Modified Golden Rule if either $\mu=0$ or $\sigma=\beta$. If $\mu=0$, cash is not required to purchase capital and hence the cost of capital investment is unaffected by changes in the rate of inflation. Thus, as shown by stockman (1981), money is superneutral in the long-run. Alternatively, if cash is required for investment $(\mu=1)$, then the cash-in-advance economy achieves the Modified Golden Rule if $\sigma=\beta$. As mentioned above, if $\sigma=\beta$, the shadow price of the cash-in-advance constraint is zero. Therefore, the cost of capital investment which requires cash-in-advance is unaffected by changes in the rate of inflation so that the economy achieves the Modified Golden Rule. Note that the optimal rate of monetary growth, $\sigma=\beta$, is, the same as in: (a) Brock's (1975) model without capital; (b) the Sidrauski (1967) model with capital (as pointed out by Dornbusch and Frenkel (1973)); and (c) overlapping generations models with neoclassical production functions as pointed out by Abel (1984a). 


\section{Cash for Consumption only}

In this section we suppose that the cash is required in advance for consumption but not for investment, i.e., that $\mu=0$. We have al ready shown that in this case money is superneutral in the long run as in Stockman (1981). Below we demonstrate that if the cash-in-advance constraint (3) is binding, then money is superneutral along the transition path as well. To analyze the dynamic behavior of the economy, we combine (6a) and (6c) to obtain

$$
B U^{\prime}\left(C_{t+1}\right)=\lambda_{t} \Pi_{t+1}
$$

Next, set $\mu$ equal to zero in $(6 b)$ and use (10) to eliminate $\lambda_{t}$ and $\lambda_{t+1}$ from (6b),

$$
B U^{\prime}\left(C_{t+2}\right)\left(f^{\prime}\left(K_{t+1}\right)+1-\delta\right) / \Pi_{t+2}=U^{\prime}\left(C_{t+1}\right) / \Pi_{t+1}
$$

Equation (1l) can be interpreted by considering a deviation from the optimal path. Suppose that in period $t$ the consumer buys an additional unit of capital, thereby reducing $M_{t+1}$ by $P_{t}$ dollars and increasing $K_{t+1}$ by one unit. In period $t+l$, the reduction in $M_{t+1}$ forces the consumer to reduce $c_{t+1}$ by $\left(1 / \Pi_{t+1}\right)$ units. The consumer's nominal income in period $t+1$ increases by $P_{t+1} f^{\prime}\left(K_{t+1}\right)$ units. If the consumer reduces gross investment in period $t+1$ by $1-\delta$ units, then $K_{t+2}$ will be unchanged and $M_{t+2}$ will increase by $P_{t+1}\left(f^{\prime}\left(K_{t+1}\right)+1-\delta\right)$. This increase in $M_{t+2}$ allows the consumer to increase $c_{t+2}$ by $\left[f^{\prime}\left(K_{t+1}+1-\delta\right)\right] / \Pi_{t+2}$ units and to maintain an unchanged path of future consumption, $c_{t+j}, j=3,4,5, \ldots$ The effect on the consumer's discounted utility is a decrease of $B U^{\prime}\left(C_{t+1}\right) / \Pi_{t+1}$ from the decrease in $C_{t+1}$ and increase 
of $\beta^{2} U^{\prime}\left(C_{t+2}\right)\left(f^{\prime}\left(k_{t+1}\right)+1-\delta\right) / \Pi_{t+2}$ from the increase in $C_{t+2}$. Equation (11) simply states that the net effect on discounted utility of a small change from the optimal path must be equal to zero.

We assume that $\sigma>\beta$ so that a steady state exists and the cash-in-advance constraint is strictly binding in the steady state. If the cash-in-advance constraint ( 3 ) is strictly binding, then, since $M_{t+1}=M_{t}+\tau_{t}$, we have

$$
P_{t} C_{t}=M_{t+1}
$$

If the (gross) growth rate of the nominal money stock is constant over time, then from (12) it follows that ${ }^{2}$

$$
\frac{\Pi_{t+2}}{\Pi_{t+1}}=\frac{c_{t+1}^{2}}{c_{t} c_{t+2}}
$$

Substituting (13) into (11) yields

$$
B C_{t} C_{t+2} U^{\prime}\left(C_{t+2}\right)\left(f^{\prime}\left(K_{t+1}\right)+1-\delta\right)=U^{\prime}\left(C_{t+1}\right) C_{t+1}^{2}
$$

Finally, we can rewrite (14) as a third-order difference equation in $k_{t}$ by first rewriting the budget constraint in (2) using the fact that $M_{t+1}=M_{t}+\tau_{t}$ to obtain

$$
c_{t}=c\left(k_{t}, k_{t+1}\right)=f\left(k_{t}\right)+(1-\delta) k_{t}-k_{t+1}
$$

2. We have assumed that the monetary transfer $\tau_{t}$ can be used to purchase consumption goods in period $t$. Alternativel $t$, if the transfer $\tau_{t}$ could not be used to purchase consumption goods in period $t$, then equation (12) would be replaced by $\mathrm{P}_{t} \mathrm{C}_{t}=\mathrm{M}_{t}$ when the cash-in-advance constraint is binding. Nevertheless, equation (13) would continue to hold if the nominal rate of monetary growth is constant over time. In addition, the first-order conditions $(6 \mathrm{a}-\mathrm{c})$ do not depend on whether $\tau_{t}$ can be used to purchase consumption goods in period $t$. Hence, the dynamic behavior of the economy is invariant to whether or not $\tau_{t}$ can be used in period $t$. 
Substituting (15) into (14) yields a third-order difference equation in $k_{t}$ which is independent of the (constant) rate of monetary growth $\sigma$. Thus provided that the cash-in-advance constraint (3) is binding, money is superneutral along the transition path as well as in the long run. ${ }^{3}$

It is worth noting that, as in the Fischer (1979) and Asako (1983) analyses of the Sidrauski (1967) model, the analysis of the effect of a change in monetary growth is interesting only if the economy is not initially in the steady state. 4 . The reason is that since the economy displays long-run superneutrality, the steady state is invariant to the capital stock. Thus, if the cash-in-advance economy is initially in the steady state, a permanent increase in the rate of monetary growth will cause an equal immediate and permanent increase in the rate of inflation and will have no effect on the capital stock, consumption or real balances . We have shown that (a) the economy with a cash-in-advance constraint only for consumption attains the Modified Golden Rule which is the same steady state attained by the corresponding non-monetary economy with an infinitely-lived representative consumer. (As mentioned before, stockman (1981) showed this result); (b) the dynamic behavior of the economy is independent of the (constant) rate of monetary growth, if the cash-in-advance constraint is binding. Note that (a) and (b) do not imply that dynamic behavior of the cash-in-advance economy is the same as in the corresponding non-monetary economy. ${ }^{5}$ Indeed, in the corresponding non-monetary economy, a consumer would

3. A more general formulation of the cash-in-advance constraint would be $\psi C_{t} \leq\left(M_{t}+\tau_{t}\right) / P_{t}$ where $0<\psi \leq 1$ is the share of consumption which must be purchased with cash. The analysis in the text assumes $\psi=1$. If $\psi<1$, then superneutrality continues to hold in the steady state, but not, in general, along the transition path. See Abel (1984b) for further discussion using a model which, at a formal level, is similar to the model with a cash-in-advance constraint for consumption only.

4. I thank an anonymous referee for pointing out this qualification.

5. I thank Robert king for bringing this point to my attention. 
equate the marginal dis-utility of reducing $C_{t+1}$ by one unit with the marginal utility of increasing $\mathrm{C}_{t+2}$ by $\mathrm{f}^{\prime}\left(\mathrm{K}_{\mathrm{t}+2}\right)+1-\delta$ units so that

$$
B U^{\prime}\left(C_{t+2}\right)\left(f^{\prime}\left(K_{t+2}\right)+1-\delta\right)=U^{\prime}\left(C_{t+1}\right)
$$

A comparison of (11) and (16) reveals that, in general, the dynamic behavior of the monetary economy differs from the dynamic behavior of the non-monetary economy. In a non-monetary economy, the marginal rate of substitution $U^{\prime}\left(C_{t+1}\right) / B U^{\prime}\left(C_{t+2}\right)$ is equated with one plus the net marginal product of capital, $1+f^{\prime}\left(k_{t+2}\right)-\delta$. In the monetary economy, this marginal rate of substitution is equated with $\left[1+f^{\prime}\left(k_{t+1}\right)-\delta\right] \Pi_{t+1} / \Pi_{t+2}$ which is one plus the net marginal product of capital, adjusted for the change in inflation tax by reducing $M_{t+1}$ and increasing $M_{t+2}$. Of course, in the steady state, with constant inflation and a constant capital stock, the marginal rate of substitution is the same in the monetary and non-monetary economies. 
III. Cash for Consumption and Investment

In this section we suppose that cash is required in advance for both consumption and investment as in (4), i.e., that $\mu=1$. We assurne that $\sigma>\beta$ so that this constraint is strictly binding in the steady state. In this case, money is not superneutral in the long run. Setting $\mu$ equal to one in (8) we obtain

$$
f^{\prime}(K)=\frac{1-\beta(1-\delta)}{\beta^{2}} \sigma
$$

Therefore, the steady state marginal product of capital is proportional to $\sigma$ so that the steady state capital stock is a decreasing function of $\sigma$ as shown by Stockman (1981).

To analyze the dynamic behavior of the economy, set $\mu$ equal to 1 in (6b) and substitute (6a) into (6b) to obtain

$$
\beta \lambda_{t+1} f^{\prime}\left(K_{t+1}\right)=U^{\prime}\left(C_{t}\right)-\beta(1-\delta) U^{\prime}\left(C_{t+1}\right)
$$

Jsing (10) to eliminate $\lambda_{t+1}$ from (18), we obtain

$$
\beta^{2} U^{\prime}\left(C_{t+2}\right) E^{\prime}\left(k_{t+1}\right)=\Pi_{t+2}\left[U^{\prime}\left(c_{t}\right)-\beta(1-\delta) U^{\prime}\left(c_{t+1}\right)\right]
$$

To interpret equation (19) consider the benefits and costs of consuming one less unit at time $t$ and using the cash to increase $k_{t+1}$ by one unit. The cost of giving up the consumption is $U^{\prime}\left(C_{t}\right)$. The benefits arrive in pexiods $t+1$ and $t+2$ : in period $t+1$, the consumer can increase consumption by $(1-\delta)$ units and maintain the previously planned path of the capital stock. Also, in period $t+1$, the consumer receives extra output 
$f^{\prime}\left(K_{t+1}\right)$ which can be sold for $P_{t+1} f^{\prime}\left(K_{t+1}\right)$ units of money. In period $t+2$, this extra money can be used to increase consumption by $f^{\prime}\left(k_{t+1}\right) / \Pi_{t+2}$ units. Thus, the present value of benefits is $\beta^{2} U^{\prime}\left(C_{t+2}\right) f^{\prime}\left(k_{t+1}\right) / \Pi_{t+2}+$ $B U^{\prime}\left(C_{t+1}\right)(1-\delta)$. Equation (19) simply states that the benefits and costs of this small change are equal.

If the cash-in-advance constraint is binding, then from (4) and (15)it follows that ${ }^{6} \quad P_{t} f\left(k_{t}\right)=M_{t+1}$ which, in terms of rates of change, is

$$
\Pi_{t+1}=\sigma \frac{f\left(K_{t}\right)}{f\left(K_{t+1}\right)}
$$

Substituting (15) and (20) into (19) yields the third-order nonlinear difference equation which governs the evolution of the capital stock

$$
\begin{gathered}
\beta^{2} f\left(K_{t+2}\right) f^{\prime}\left(K_{t+1}\right) U^{\prime}\left(C\left(K_{t+2}, K_{t+3}\right)\right)-\sigma f\left(K_{t+1}\right)\left\{U^{\prime}\left(C\left(K_{t}, K_{t+1}\right)\right)\right. \\
\left.-\beta(1-\delta) U^{\prime}\left(C\left(k_{t+1}, k_{t+2}\right)\right)\right\}=0
\end{gathered}
$$

The strategy of the analysis of dynamics is to linearize (21) around the steady state $\mathrm{K}_{t}=\mathrm{K}$ and then to analyze the characteristic roots of the linearized system. Let $\tilde{k}_{t} \equiv k_{t}-k$ denote the deviation of $k_{t}$ from its steady state value. Then linearizing (2l) around $k_{t}=k$ yields

$$
\alpha_{3} \tilde{K}_{t+3}+\alpha_{2} \tilde{K}_{t+2}+\alpha_{1} \tilde{K}_{t+1}+\alpha_{0} \tilde{K}_{t}=0
$$

6. If the monetary transfer $\tau_{t}$ cannot be used to purchase goods in period $t$, then $P_{t} f\left(K_{t}\right)=M_{t}$ if the cash-in-advance constraint is binding. However, the dynamics are unaffected by whether $\tau_{t}$ can be used to purchase goods in period $t$. See footnote 2 . 
where

$$
\alpha_{3}=-\beta^{2} f f^{\prime} U^{\prime \prime}>0
$$

$$
\begin{gathered}
\alpha_{2}=\beta^{2} f^{\prime 2} U^{\prime}+\beta^{2} f f^{\prime} U^{\prime \prime}\left[f^{\prime}+1-\delta\right]-\sigma f \beta(1-\delta) U^{\prime \prime} \\
\alpha_{1}=\beta^{2} f f^{\prime \prime} U^{\prime}-\sigma f^{\prime} U^{\prime}[1-\beta(1-\delta)]+\sigma f U^{\prime \prime}\left[1+\beta(1-\delta)\left(f^{\prime}+1-\delta\right)\right]<0 \\
\alpha_{0}=-\sigma f U^{\prime \prime}\left[f^{\prime}+1-\delta\right]>0
\end{gathered}
$$

The associated characteristic equation is

$$
h(z) \equiv \alpha_{3} z^{3}+\alpha_{2} z^{2}+\alpha_{1} z+\alpha_{0}=0
$$

Let $\omega_{i}=1,2,3$ be the characteristic roots, so that $h\left(\omega_{i}\right)=0$. We order the roots so that $\omega_{1} \leq \omega_{2} \leq \omega_{3}$.

our next step is to show that

$$
\begin{gathered}
\omega_{1}<-1 \\
0<\omega_{2}<1 \\
\omega_{3}>1
\end{gathered}
$$

so that there is a saddle path to the steady state. It is shown in Appendix A that

$$
\begin{gathered}
h(0)=\alpha_{0}>0 \\
h(1)=\sum_{i=0}^{3} \alpha_{i}<0 \\
h(-1)=\sum_{i=0}^{3}(-1)^{i} \alpha_{i}>0
\end{gathered}
$$


It follows immediately from $(25 a)$ and $(25 b)$ that $h(z)=0$ has at least one real root between 0 and 1 . From Descartes Rules of Signs, the fact that there are two changes of sign in the coefficients of $h(z)=0$ indicates that there are either zero or two positive real roots. Since we have located one real root between 0 and 1 , these must be two positive real roots. Furthermore, the other real root must be greater than 1 . Finally, the remaining root is real and negative. It follows immediately from $(25 a, c)$ that the negative root is not between -1 and 0 . Therefore, the negative root is less than -1 .

We have now demonstrated that only one of the three characteristic roots has modulus less than one. Furthermore, this stable root is positive so that the capital stock approaches its steady state monotonically. If the capital stock $\mathrm{K}_{t}$ is below the steady state capital stock, then the monotonic approach to the steady state implies that $k_{t+1}>k_{t}$ so that from equation $(20)$, we have $\Pi_{t+1}<\sigma$. As the steady state is approached, the real money supply increases over time and the rate of inflation increases toward its steady state value of $\sigma$. This behavior of the capital stock, real balances and the rate of inflation is qualitatively the same as in the Sidrauski model, as discussed by Fischer (1979). 
IV. The Effect of Monetary Growth on the Speed of Adjustment

In this section we examine the effect of a permanent change in

monetary growth on the speed of adjustment with a binding cash-in-advance constraint on consumption and investment. In order to make the analysis more tractable we restrict the preferences and technology of our model economy. Specifically, we assume that utility function is isoelastic so that

$$
U\left(C_{t}\right)=\frac{C_{t}^{1-\rho}-1}{1-\rho} \quad \rho>0
$$

We assume that production function is Cobb-Douglas

$$
f\left(K_{t}\right)=A K_{t}^{\phi} \quad 0<\phi<1
$$

Therefore in the steady state we have

$$
C=A K^{\phi}-\delta \mathrm{K}
$$

Using equations (26)-(28), the characteristic equation (23) can be simplified considerably. It is shown in Appendix B that the characteristic equation can be written as

$$
h(z)=\left[(1-\beta(1-\delta)) \frac{\sigma}{\beta^{2}}+(1-\delta)\right] g(z)+j(z)=0
$$

where

$$
\begin{gathered}
g(z)=\left(\frac{1}{\rho}-1\right) z^{2}-\left(\frac{1}{\rho \phi}+\frac{\beta(1-\delta)}{1-\beta(1-\delta)}\right) z+\frac{1}{1-\beta(1-\delta)} \\
j(z)=z\left\{(z-1)\left(z+\frac{1}{1-\beta(1-\delta)}\right)-\frac{1}{\rho}(1-\delta+\delta \phi)\left(z-\frac{1}{\phi}\right)\right\}
\end{gathered}
$$


Note that the polynomials $g(z)$ and $j(z)$ are independent of $\sigma$. The characteristic equation is a cubic equation in $\mathrm{z}$ but is linear in the monetary growth rate $\sigma$.

The effect of an increase in $\sigma$ on the stable root $\omega_{2}$ is calculated by applying the implicit function theorem to (29a) to obtain

$$
\frac{d \omega_{2}}{d \sigma}=-\frac{\partial h\left(\omega_{2}\right)}{\partial \sigma}, \frac{\partial h\left(\omega_{2}\right)}{\partial z}
$$

It follows from $(25 a, b)$ that $\frac{\partial h\left(\omega_{2}\right)}{\partial z}<0$ so that $(30)$ implies

$$
\operatorname{sign}\left(\frac{d \omega_{2}}{d \sigma}\right)=\operatorname{sign}\left(\frac{\partial h\left(\omega_{2}\right)}{\partial \sigma}\right)=\operatorname{sign}\left(g\left(\omega_{2}\right)\right)
$$

The second equality in (31) follows directly from (29a) and the fact that $1-B(1-\delta)>0$. In Appendix $C$ we prove the following lemma

Lemma. $\operatorname{sign}\left(g\left(\omega_{2}\right)\right)=\operatorname{sign}(g(1-\delta+\delta \phi))$.

To calculate $g(1-\delta+\delta \phi)$, we use $(29 b)$ to obtain

$$
g(1-\delta+\delta \phi)=(\phi-1) s(\rho, \phi, \delta, \beta)
$$

where $\quad s(\rho, \phi, \delta, \beta)=(1-\delta+\delta \phi)\left[\frac{1}{\rho \phi}+\left(\frac{1}{\rho}-1\right) \delta\right]-\frac{\delta}{1-\beta(1-\delta)}$

Since $\phi<1$, it follows from (31), the Lemma and (32a) that

$$
\operatorname{sign} \frac{d \omega_{2}}{d \sigma}=-\operatorname{sign} s(\rho, \phi, \delta, \beta)
$$


Before commenting on the implications of (33), we show that the speed of adjustment of the linearized economy is $1-\omega_{2}$. In the linearized economy, the movement of the capital stock is governed by the following equation

$$
\tilde{\mathrm{K}}_{t}=\tilde{\mathrm{K}}_{0}\left(\omega_{2}\right)^{t}
$$

Note that the unstable roots $\left(\omega_{1}\right.$ and $\left.\omega_{3}\right)$ have been excluded from (34). It follows from (34) that

$$
\tilde{\mathrm{k}}_{t}-\tilde{\mathrm{k}}_{t-1}=\left(\omega_{2}-1\right) \tilde{\mathrm{K}}_{t-1}
$$

Recalling that $\tilde{\mathrm{K}}_{t}$ is defined as the deviation of $\mathrm{K}_{t}$ from the steady state capital stock $\mathrm{K},(35)$ becomes

$$
\Delta \mathrm{K}_{t}=\left(1-\omega_{2}\right)\left(\mathrm{K}-\mathrm{K}_{\mathrm{t}-1}\right)
$$

Thus, $1-w_{2}$ is the fraction of the gap between the current capital stock and the steady state capital stock which is closed in one period. It follows immediately from (33) that the direction of the effect of an increase in $\sigma$ on the speed of adjustment is

$$
\operatorname{sign} \frac{d\left(1-\omega_{2}\right)}{d \sigma}=\operatorname{sign} s(\rho, \phi, \delta, \beta)
$$

Equation (37) along with the definition of $s(\rho, \phi, \delta, \beta)$ in $(32 b)$ indicates the direction of the effect of an increase in monetary growth on the adjustment speed. Thus, given the two technological parameters $\phi$ and $\delta$ and the two preference parameters $\rho$ and $\beta$, we can easily determine the direction of the 
effect on the adjustment speed. It is interesting to examine two special cases: (a) $\delta=0$; and (b) $\delta=1$.

If $\delta=0$, it follows immediately from $(32 \mathrm{~b})$ that $s(\rho, \phi, \delta, \beta)=\frac{1}{\rho \phi}>0$ and hence $\frac{d\left(1-\omega_{2}\right)}{d \sigma}>0$. In this case we obtain the unambiguous result that an increase in the monetary growth rate $\sigma$ leads to an increase in the adjustment speed of the economy.

The results are dramatically different if capital depreciates completely after one period, i.e., $\delta=1$. In this case, $s(\rho, \phi, \delta, \beta)=(1-\rho)\left(\frac{1+\phi}{\rho}\right)$. Therefore, an increase in the rate of monetary growth increases (decreases.) the speed of adjustment if the elasticity of marginal utility $\rho$ is less (greater) than one. If $\rho=1$, i.e., if utility is logarithmic, the adj stment speed of the economy is invariant to $\sigma$.

Thus far, we have shown that the effect of increased monetary growth on the adjustment speed $1-\omega_{2}$ depends on the sign of $s(\rho, \phi, \delta, \beta)$. To calculate the effect on net investment, given the capital stock $k_{t}$, we differentiate (36) with respect to $\sigma$ to obtain

$$
\frac{d \Delta K_{t+1}}{d \sigma}=-\frac{d \omega_{2}}{d \sigma}\left(K-K_{t}\right)+\left(1-\omega_{2}\right) \frac{d K}{d \sigma}
$$

Since $1-\omega_{2}>0$ and $\frac{d K}{d \sigma}<0$, the second of the two terms in (38) is negative. Thus, for instance, if $\delta=1$ and $\rho=1$ so that $\frac{d \omega_{2}}{d \sigma}=0$, an increase in monetary growth decreases the rate of net investment. More generaliy, however, it is possible for the two terms in (38) to be of opposite sign and the effect on net investment could be either positive or negative. 
V. Concluding Remarks

The analysis in this paper has examined the dynamic behavior along the (linearized) transition path in Stockman's (1981) cash-in-advance model as Fischer (1979) and Asako (1983) have analyzed the (linearized) transition path in the sidrauski (1967) model. In particular, these analyses of the transition path have focussed on the effect of a permanent increase in monetary growth on the speed of adjustment of the economy. We have presented some general results for the cash-in-advance model which may be compared with the results for the sidrauski model. For example, if the cash-in-advance constraint applies to investment as well as consumption, and if capital does not depreciate, then an increase in monetary growth increases the adjustment speed of economy; except for the logarithmic case (in which the speed of adjustment is invariant to the rate of monetary growth), Fischer (1979) also found that higher monetary growth leads to faster adjustment in the Sidrauski model. Alternatively, we showed that if capital depreciates completely after one period in the cash-in-advance model, then higher monetary growth leads to faster (slower) (the same) speed of adjustment if the elasticity of marginal utility is less than (greater than) (equal) to one; these findings are qualitatively the same as in Asako's (1983) formulation of the Sidrauski model in which money and consumption are perfect complements in the utility function.

The similarity of results between some specifications of the cash-inadvance model and some specifications of the Sidrauski model is superficial and may mask an important underlying difference. The results derived by Fischer and Asako for the Sidrauski model do not depend on the specification of technology, except for the usual concavity assumptions. Although these studies explicitly assume zero depreciation, the production function in these 
papers, $f\left(K_{t}\right)$, could be interpreted as $f\left(K_{t}\right)=\tilde{f}\left(K_{t}\right)-\delta K_{t}$ where $\tilde{\dot{f}}$ is gross output. However, the results for the cash-in-advance model depend crucially on the specification of technology. The budget constraint (2) relates net investment $k_{t+1}-K_{t}$ to net output $f\left(k_{t}\right)-\delta K_{t}$ (and other variables), whereas the cash-in-advance constraint (4) relates net investment to depreciation $\delta \mathrm{K}_{\mathrm{t}}$ (and other variables). Because the capital stock enters two constraints in different forms $\left(f\left(K_{t}\right)-\delta k_{t} v s\right.$. $\left.\delta \mathrm{K}_{t}\right)$, it is no longer sufficient simply to specify the net production function wi thout specifying the gross production function and depreciation separately. As we have emphasized, the effect on the adjustment speed of a change in the monetary growth rate can differ dramatically depending on the rate of depreciation. 
Appendix A

In this Appendix we verify the inequalities in $(25 a-c)$ in the text. Inequality (25a) follows immediately from (22e). To derive (25b), we add together $(22 \mathrm{~b}-\mathrm{e})$ to obtain

$$
\begin{gathered}
\sum_{i=0}^{3} \alpha_{i}=\beta^{2}\left\{f^{\prime 2} U^{\prime}\right. \\
\left.+f f^{\prime \prime} U^{\prime}+f^{\prime} U^{\prime \prime}\left[f^{\prime}-\delta\right]\right\}-\sigma\left\{f U ^ { \prime \prime } \left[\beta(1-\delta)+f^{\prime}-\delta\right.\right. \\
\left.\left.-\beta(1-\delta)\left(f^{\prime}+1-\delta\right)\right]+f^{\prime} U^{\prime}[1-\beta(1-\delta)]\right\}
\end{gathered}
$$

Recalling from $(17)$ that $\beta^{2} f^{\prime}=[1-\beta(1-\delta)] \sigma$, equation $(A-1)$ can be rewritten as

$$
\sum_{i=0}^{3} \alpha_{i}=\beta^{2}\left\{f f^{\prime \prime} U^{\prime}+f f^{\prime} U^{\prime \prime}\left[f^{\prime}-\delta\right]\right\}-\sigma f U^{\prime \prime}\left(f^{\prime}-\delta\right)(1-\beta(1-\delta))
$$

Using (17) once again yields

$$
\sum_{i=0}^{3} \alpha_{i}=\beta^{2} f f^{\prime \prime} U^{\prime}<0
$$

which verifies $(25 \mathrm{~b})$.

To verify $(25 c)$ we observe from $(22 b-c)$ that

$$
\begin{aligned}
\sum_{i=0}^{3}(-1)^{i} \alpha_{i} & =\beta^{2}\left\{f f^{\prime} U^{\prime \prime}+f^{\prime 2} U^{\prime}+f f^{\prime} U^{\prime \prime}\left[f^{\prime}+1-\delta\right]-f f^{\prime \prime} U^{\prime}\right\} \\
& +\sigma\left\{-f \beta(1-\delta) U^{\prime \prime}+f^{\prime} U^{\prime}[1-\beta(1-\delta)]-f U^{\prime \prime}\left[1+\beta(1-\delta)\left(f^{\prime}+1-\delta\right)\right]\right. \\
& \left.-f U^{\prime \prime}\left[f^{\prime}+1-\delta\right]\right\}
\end{aligned}
$$

Using (17) we obtain

$$
\begin{aligned}
\sum_{i=0}^{3}(-1)^{i} \alpha_{i} & =\beta^{2}\left\{\left(2 f^{\prime}{ }^{2}-f f^{\prime \prime}\right) U^{\prime}+f f^{\prime} U^{\prime \prime}\left[f^{\prime}+2-\delta\right]\right\}-\sigma f U^{\prime \prime}\left\{\beta(1-\delta)\left(f^{\prime}+2-\delta\right)\right. \\
& \left.+\left(f^{\prime}+2-\delta\right)\right\}
\end{aligned}
$$

Combining terms in $\left(f^{\prime}+2-\delta\right)$ and using (17) yields

$$
\sum_{i=0}^{3}(-1)^{i} \alpha_{i}=\beta^{2}\left(2 f^{\prime}, f f^{\prime \prime}\right) U^{\prime}-2 \sigma f U^{\prime \prime} \beta(1-\delta)\left[f^{\prime}+2-\delta\right]>0
$$


In this Appendix we show that with isoelastic utility as in (26) and a cobb-Douglas production function as in (27) the characteristic equation is given by $(29 a-c)$.

Since $\alpha_{3}>0$, the characteristic equation (23) can be rewritten as

$$
\mathrm{h} *(\mathrm{z})=\mathrm{z}^{3}+\alpha_{2} * \mathrm{z}^{2}+\alpha_{1} * \mathrm{z}+\alpha_{0} *=0
$$

where

$$
\alpha_{i} * \equiv \frac{\alpha_{i}}{\alpha_{3}} \quad i=0,1,2
$$

Dividing (22e) by (22b) and using (17) immediately yields

$$
\alpha_{0}^{*}=\left(f^{\prime}+1-\delta\right) \frac{1}{1-\beta(1-\delta)}
$$

Dividing (22d) by (22b) and using (17) yields

$$
\alpha_{1}^{*}=\left(\frac{f^{\prime}}{f}-\frac{f^{\prime \prime}}{f^{\prime}}\right) \frac{U^{\prime}}{U^{\prime \prime}}-\frac{1+\beta(1-\delta)\left(f^{\prime}+1-\delta\right)}{I-\beta(1-\delta)}
$$

With the Cobb-Douglas production function in $(27), f^{\prime} / f=\phi / K$ and $f^{\prime \prime} / f^{\prime}=$ $(\phi-1) / K$ so that $f^{\prime} / f-f^{\prime \prime} / f^{\prime}=1 / K$. Therefore, $(B-3)$ can be rewritten as

$$
\alpha_{1}^{*}=\frac{-C}{K} \frac{U^{\prime}}{-C U^{\prime \prime}}-\frac{1+\beta(1-\delta)\left(E^{\prime}+1-\delta\right)}{1-\beta(1-\delta)}
$$

From (28), $C / K=f^{\prime} / \phi-\delta$ so that we obtain

$$
\alpha_{1} *=\frac{-1}{\rho}\left(\frac{1}{\phi} f^{\prime}-\delta\right)-\frac{1+\beta(1-\delta)\left(f^{\prime}+1-\delta\right)}{1-\beta(1-\delta)}
$$

Rearranging (B-5) yields 


$$
\alpha_{1}{ }^{*}=\left(f^{\prime}+1-\delta\right)\left(\frac{-1}{\rho \phi}-\frac{\beta(1-\delta)}{1-\beta(1-\delta)}\right)+\frac{1-\delta+\delta \phi}{\rho \phi}-\frac{1}{1-\beta(1-\delta)}
$$

To calculate $\alpha_{2} *$, divide (22c) by $(22 b)$ and use (17) to obtain

$$
\alpha_{2}{ }^{*}=-\left(f^{\prime}+1-\delta\right)-\frac{U^{\prime} f^{\prime}}{U^{\prime \prime} f}+\frac{\beta(1-\delta)}{1-\beta(1-\delta)}
$$

Since $f^{\prime} / f=\phi / K$ and $-C U^{\prime \prime} / U^{\prime}=\rho$, we have

$$
-\frac{U^{\prime} f^{\prime}}{U^{\prime \prime} f}=\phi \frac{C}{K} \frac{1}{\rho}=\frac{1}{\rho} f^{\prime}-\frac{\delta \phi}{\rho}
$$

where the second inequality uses the fact that $c / K=f^{\prime} / \phi-\delta$. Substituting $(B-8)$ into $(B-7)$ and rearranging yields

$$
\alpha_{2}{ }^{*}=\left(f^{\prime}+1-\delta\right)\left(\frac{1}{\rho}-1\right)-\frac{1}{\rho}(1-\delta+\delta \phi)+\frac{\beta(1-\delta)}{1-\beta(1-\delta)}
$$

Observing that $\alpha_{3}{ }^{*}=1$, the characteristic equation can be written using $(B-2),(B-6),(B-9)$ and $(29 b)$ as

$$
h(z)=\left(f^{\prime}+1-\delta\right) g(z)+j^{*}(z)
$$

where $j^{*}(z)=z\left[z^{2}+\left[\frac{\beta(1-\delta)}{1-\beta(1-\delta)}-\frac{1}{\rho}(1-\delta+\delta \phi)\right] z+\frac{1}{\rho \phi}(1-\delta+\delta \phi)-\frac{1}{1-\beta(1-\delta)}\right\}$

Rearranging $(B-10 b)$ reveals that $j *(z) \equiv j(z)$ where $j(z)$ is given by $(29 c)$. It follows from (17) that

$$
f^{\prime}+1-\delta=(1-\beta(1-\delta)) \frac{\sigma}{\beta^{2}}+(1-\delta)
$$

Substituting ( $\mathrm{B}-11)$ into ( $\mathrm{B}-10 \mathrm{O})$ yields the characteristic equation in (29). 
Appendix C

In this Appendix we prove the Lemma: $\operatorname{sign}\left(g\left(\omega_{2}\right)\right)=\operatorname{sign}(g(1-\delta+\delta \phi))$. First observe from $(29 b)$ that $g(0)=\frac{1}{1-\beta(1-\delta)}>0$ and $g(1)=\frac{\phi-1}{\rho \phi}<0$. Therefore, there exists a $\hat{\mathrm{z}}$ in $(0,1)$ such that

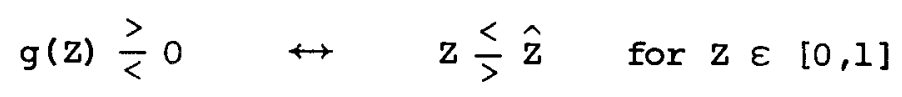

Next, observe that

$$
\mathrm{h}(\hat{\mathrm{z}}) \frac{\geq}{<} 0 \quad \leftrightarrow \omega_{2} \frac{\geq}{<} \hat{\mathrm{z}} \leftrightarrow \mathrm{g}\left(\omega_{2}\right) \leq 0
$$

The first equivalence in (C-2) follows from the facts that $\omega_{2}$ is the only real root of $h(z)=0$ in the interval $[0,1]$ and $h(0)>0, h(1)<0$. Therefore, for $\mathrm{z} \varepsilon[0,1], h(z) \frac{\geq}{<} 0$ as $z_{>}^{\leqslant}-\omega_{2}$. The second equivalence in $(C-2)$ follows from $(C-1)$. Next observe from (29a) that

$$
h(\hat{z})=j(\hat{z})
$$

since $g(\hat{z})=0$. Another implication of $g(\hat{z})=0$ is, from (29b),

$$
(\hat{z}-1)\left(\hat{z}+\frac{1}{1-\beta(1-\delta)}\right)=\frac{1}{\rho} \hat{z}\left(\hat{z}-\frac{1}{\phi}\right)
$$

Substituting (C-4) into (29c) and then using (C-3) implies

$$
h(\hat{z})=\hat{z} \frac{1}{\rho}\left(\hat{z}-\frac{1}{\phi}\right)(\hat{z}-(1-\delta+\delta \phi))
$$

Since $0<\hat{z}<1$, it follows from $(C-1)$ and $(C-5)$ that

$$
\operatorname{sign}(h(\hat{z}))=-\operatorname{sign}(g(1-\delta+\delta \phi))
$$


Finally $(c-2)$ and $(c-6)$ imply that

$$
\operatorname{sign}\left(g\left(\omega_{2}\right)\right)=\operatorname{sign}(g(1-\delta+\delta \phi))
$$


Abel, Andrew B., "Optimal Monetary Growth in Overlapping Generations Models," mimeo, Harvard University, (1984), a.

, "Monetary Growth and Capital Accumulation on the Transition Path," mimeo, Harvard University, (1984), b.

Asako, Kazumi, "The Utility Function and the Superneutrality of Money on the Transition Path," Econometrica 51,5 (September 1983), 1593-6.

Brock, William A., "A Simple Perfect Foresight Monetary Model," Journal of Monetary Economics 1 (1975), 133-150.

Dornbusch, Rudiger and Jacob A. Frenkel, "Inflation and Growth : Alternative Approaches," Journal of Money, Credit, and Banking 5 (1973), 141-156.

Fischer, Stanley, "Capital Accumulation on the Transition Path in a Monetary Optimizing Model," Econometrica 47,6 (November, 1979), 1433-1439.

Samuelson, Paul A., "The Two-Part Golden Rule Deduced as the Asymptotic Turnpike of Catenary Motions," Western Economic Journal (March 1968).

Sidrauski, Miguel, "Rational Choice and Patterns of Growth in a Monetary Economy," American Economic Review, Papers and Proceedings, 57 (1967), $534-44$.

Stockman, Alan C., "Anticipated Inflation and the Capital stock in a Cash-inAdvance Economy," Journal of Monetary Economics 8,3 (November 1981), 387-393. 